\title{
Uso do clorofilômetro no monitoramento nutricional de arroz irrigado com vistas ao manejo da adubação nitrogenada ${ }^{1}$
}

\author{
Elisandra Pocojeski², Leandro Souza da Silva³, Simone Kaefer ${ }^{4}$, \\ Vagner João Moro ${ }^{5}$, Gustavo Griebeler ${ }^{6}$ \\ http://dx.doi.org/10.1590/0034-737X201562030011
}

\begin{abstract}
RESUMO
O clorofilômetro pode auxiliar no manejo da adubação nitrogenada em cobertura, não havendo, porém, um valor crítico de leitura que se correlacione com a produtividade de grãos. O objetivo deste trabalho foi monitorar o teor de nitrogênio (N), nas plantas de arroz irrigado dos cultivares IRGA 422CL e IRGA 424, com o uso do clorofilômetro, e associar as leituras com a produção de matérias verde e seca das plantas e com a produtividade de grãos. Foram desenvolvidos dois experimentos, nas safras 2007/08 e 2008/09, com doses $N$ para a $1^{a}$ e $2^{a}$ adubação de cobertura, sendo, posteriormente, realizadas as leituras SPAD (Soil Plant Analysis Development) e determinados a produção de matérias verde e seca, os teores de $\mathrm{N}$ no tecido das plantas e de $\mathrm{N}$ acumulado e a produtividade de grãos. Houve efeito da $1^{\mathrm{a}}$ e $2^{\mathrm{a}}$ aplicação de $\mathrm{N}$ nas leituras do clorofilômetro ao longo do ciclo, porém, as leituras SPAD tornaram-se semelhantes para todos os tratamentos com o passar do tempo. A produção de matérias verde e seca e de $\mathrm{N}$ acumulado responderam linearmente às doses de $\mathrm{N}$. Não houve efeito de interação para as doses de $\mathrm{N}$ e produtividade de grãos, porém, a resposta de produtividade de grãos, em função das doses de $\mathrm{N}$, obedeceu a uma relação quadrática, em ambos os experimentos. A leitura SPAD avalia o estado nutricional das plantas de arroz irrigado, mas não produz uma informação precisa sobre a necessidade de aplicação de $\mathrm{N}$ com reflexos na produtividade. Portanto, associá-la a outros parâmetros, como à produção de matérias verde e seca da planta pode auxiliar na interpretação e no ajuste da dose de $\mathrm{N}$ a ser aplicada em cobertura.
\end{abstract}

Palavras-chave: Oryza sativa, matéria verde/seca, produtividade de grãos, manejo do nitrogênio, solos de várzea.

\section{ABSTRACT}

\section{Monitoring nutritional status of flooded rice cultivars by chlorophyll meter in nitrogen fertilization management}

Chlorophyll meter can help in the management of topdressing nitrogen fertilization, however, there isn't a critical reading value with a satisfactory relationship with grain yield. The objective of this study was to monitor the nitrogen (N) level in flooded rice plants, cultivars IRGA 422CL and IRGA 424, using the chlorophyll meter and associating the readings with green/dry matter production and grain yield. Two experiments were carried out in the crop years $2007 / 08$ and 2008/09 with $\mathrm{N}$ rates for the $1^{\text {st }}$ and $2^{\text {nd }}$ topdressing fertilizations, followed by SPAD (Soil Plant Analysis Development) readings and determination of green/dry mater, $\mathrm{N}$ content in plant tissue, accumulated $\mathrm{N}$

\footnotetext{
Submetido em 12/11/2013 e aprovado em 15/05/2015.

${ }^{1}$ Parte da Tese de Doutorado do primeiro autor apresentada ao Programa de Pós Graduação em Ciência do Solo da Universidade Federal de Santa Maria.

2'Universidade Tecnológica Federal do Paraná, Dois Vizinhos, Paraná, Brasil. elisandrap@utfpr.edu.br

${ }_{3}^{3}$ Universidade Federal de Santa Maria, Departamento de Solos, Santa Maria, Rio Grande do Sul, Brasil. leandro@smail.ufsm.br

${ }^{4}$ Emater, Porto Velho, Rondônia, Brasil. sikaeffer@ hotmail.com

${ }^{5}$ Universidade Federal de Santa Maria, Programa de Pós-Graduação em Ciência do Solo, Santa Maria, Rio Grande do Sul, Brasil. vagnermoro@yahoo.com.br.

${ }^{6}$ Universidade Federal de Santa Maria, Programa de Pós Graduação em Ciência do Solo, Santa Maria, Rio Grande do Sul, Brasil. gustavogriebeler@hotmail.com

*Autor para correspondência: leandro@smail.ufsm.br
}

Rev. Ceres, Viçosa, v. 62, n.3, p. 310-318, mai-jun, 2015 
and grain yield. It was found effect of the $1^{\text {st }}$ and $2^{\text {nd }} \mathrm{N}$ applications on chlorophyll meter readings along the cycle, however, the SPAD readings became similar with time for all treatments. Green/dry matter production and accumulated $\mathrm{N}$ responded linearly to the $\mathrm{N}$ rates. There was no effect of interaction for $\mathrm{N}$ rates and grain yield, but the response of grain yield as a function of $\mathrm{N}$ rates was described by a quadratic equation in both experiments. SPAD readings evaluated the nutritional status of flooded rice plants but did not show accurate information about $\mathrm{N}$ needs with reflexes in the yield. Therefore, chlorophyll meter readings could be associated to other parameters, such as green/ dry mater to help interpretation and adjustment of $\mathrm{N}$ topdressing fertilization.

Key words: Oryza sativa, green/dry matter, grain yield, management of nitrogen, lowland soils.

\section{INTRODUÇÃO}

A análise do tecido de plantas pode ser utilizada para identificar os níveis de suficiência ou de deficiência de nutrientes na planta, com vistas à adequação da adubação das culturas. No manejo da adubação das culturas anuais, a recomendação tem maior destaque, tendo em vista o parcelamento da adubação nitrogenada. Entretanto, avaliações do teor de $\mathrm{N}$ no tecido vegetal durante o ciclo de cultivo, especialmente na fase reprodutiva do arroz, apresentam a desvantagem de não possibilitarem correção da deficiência do nutriente no mesmo ano agrícola, sendo apenas úteis para identificar se houve falta ou excesso desse nutriente em um determinado estádio de desenvolvimento da planta (Argenta et al., 2002). Dentre os métodos que já estão sendo testados e, ou, utilizados para auxiliar a análise do tecido de plantas, especialmente para $\mathrm{N}$, destaca-se o medidor portátil de clorofila (clorofilômetro). O medidor de clorofila, modelo SPAD-502, fornece leituras que correspondem ao teor do pigmento clorofila presente na folha. Os comprimentos de onda escolhidos para medição do teor de clorofila situam-se na faixa do vermelho, em que a absorbância é alta e não é afetada pelos carotenoides, e do infravermelho, em que a absorbância é extremamente baixa. A luz transmitida, que depende do tom verde da folha, é convertida em sinais elétricos e a razão das intensidades da luz transmitida nas duas regiões de comprimentos de ondas corresponde a um valor numérico, chamado de leitura SPAD (Soil Plant Analysis Development), que é mostrado num visor (Fontes, 2001). Assim, o clorofilômetro mede um valor correspondente ao do teor de clorofila na folha, sem destruí-la, e, indiretamente, o do teor de $\mathrm{N}$ no tecido pode ser estimado (Argenta et al., 2001), já que ambos estão relacionados.

O clorofilômetro, ou método SPAD, foi testado para a cultura do arroz para avaliação do teor de $\mathrm{N}$ na planta e da necessidade de aplicação de $\mathrm{N}$ em cobertura (Turner
\& Jund, 1991; Peng et al., 1993; 1996). Peng et al. (1993) determinaram um valor crítico de 35 unidades SPAD para os estádios de pré-panícula e de iniciação da panícula, para o cultivar de arroz irrigado IR72. Um valor SPAD crítico é a leitura SPAD para um nível crítico de $\mathrm{N}$ na planta, abaixo do qual a cultura não irá atingir seu potencial produtivo. Estudo desenvolvido por Pocojeski (2007), utilizando diferentes doses de $\mathrm{N}$ e cultivares de arroz irrigado, cultivados nos Estados do RS e SC, demonstrou que o clorofilômetro tem potencial para ser utilizado independentemente do cultivar e que há relação entre as leituras do clorofilômetro e o teor de $\mathrm{N}$ da folha, ou seja, há um aumento das leituras SPAD conforme aumentam as doses de $\mathrm{N}$ aplicadas, porém esta relação existe somente entre a folha em que é realizada a leitura e determinado o teor de $\mathrm{N}$, não sendo válida para qualquer folha ou parte da planta. A leitura do clorofilômetro e, consequentemente, a estimativa indireta do teor de $\mathrm{N}$ da folha em que é realizada a leitura, nem sempre esta relacionada com o estado nutricional da planta, principalmente pelo efeito de diluição de $\mathrm{N}$ na planta com o crescimento da parte aérea (Pocojeski, 2007, Pit et al., 2007, Pocojeski et al., 2008).

Assim, plantas com alta produção de matéria verde podem apresentar menores valores de leitura SPAD do que plantas com menor produção desta, o que não descreve o estado nutricional da cultura em si. A partir desses resultados, Pocojeski (2007), Pit et al. (2007) e Pocojeski et al. (2008) destacam a necessidade de se utilizar não somente o valor da leitura SPAD, mas também outros parâmetros da planta, como produção de matéria verde ou seca e, ou, $\mathrm{N}$ acumulado, à semelhança do que já é realizado, por exemplo, no sistema de recomendação de adubação denominado "Ricecheck" empregado na Austrália (Ricecheck, 2006). Nesse sistema, leva-se em consideração, principalmente, o grupo varietal, o peso da matéria fresca, o teor de $\mathrm{N}$ do tecido das plantas no estádio de iniciação de panícula e o N 
acumulado no tecido das plantas (dependente da matéria seca produzida). Com base nos valores obtidos, o agricultor pode ajustar a dose de fertilizante nitrogenado a aplicar na lavoura.

O objetivo deste trabalho foi monitorar o nível de $\mathrm{N}$ das plantas de arroz irrigado, dos cultivares IRGA 422CL e IRGA 424, com o uso do clorofilômetro ao longo do ciclo de cultivo e associar as leituras com a produção de matérias verde e seca das plantas à produtividade de grãos.

\section{MATERIAL E MÉTODOS}

Foram conduzidos dois experimentos, em condições de campo, nas safras 2007/2008 e 2008/2009, na área experimental do Departamento de Solos, da Universidade Federal de Santa Maria, Santa Maria, RS, em solo classificado como Planossolo Háplico Eutrófico arênico (Embrapa, 2013), sendo o clima da região do tipo Cfa, subtropical úmido, segundo classificação climática de Köppen (Moreno, 1961). O delineamento experimental utilizado em ambos os experimentos foi o de blocos ao acaso, com parcela subdividida e com quatro repetições por tratamento. As parcelas principais foram compostas de $5 \mathrm{~m} \mathrm{x} 16 \mathrm{~m}\left(80 \mathrm{~m}^{2}\right)$, sendo posteriormente divididas em subparcelas de $5 \mathrm{~m} \mathrm{x} 4 \mathrm{~m}\left(20 \mathrm{~m}^{2}\right)$ em função dos tratamentos. Para a adubação, realizada na semeadura, foram utilizados 100 e $250 \mathrm{~kg} \mathrm{ha}^{-1}$ da fórmula 5-20-30 de $\mathrm{N}-\mathrm{P}_{2} \mathrm{O}_{5}-\mathrm{K}_{2} \mathrm{O}$, para o primeiro e segundo experimento, respectivamente. A área experimental apresentava teor de matéria orgânica do solo de $26 \mathrm{~g} \mathrm{~kg}^{-1}$, classificado como médio (CQFS RS/SC, 2004).

\section{Experimento 1}

A semeadura mecanizada, na safra 2007/2008, foi realizada no dia 13/11/2007, a uma profundidade de aproximadamente $3 \mathrm{~cm}$, com densidade de sementes de $110 \mathrm{~kg} \mathrm{ha}^{-1}$ (corrigido o poder germinativo) do cultivar de arroz irrigado IRGA 422 CL, de ciclo médio, de aproximadamente 121 dias, em espaçamento entre linhas de $0,17 \mathrm{~m}$. O controle de plantas invasoras foi efetuado em pós-emergência, no dia 03/12/2007 (15 dias após a emergência das plântulas), com uma aplicação de Imazetapir + Imazapic, na dose de 1,5 $\mathrm{L} \mathrm{ha}^{-1}$. Os tratamentos da parcela principal consistiram em cinco doses de $\mathrm{N}\left(0,40,63,80\right.$ e $\left.120 \mathrm{~kg} \mathrm{ha}^{-1}\right)$, sendo a dose de $63 \mathrm{~kg} \mathrm{ha}^{-1}$ correspondente a $60 \%$ da dose de $\mathrm{N}$ a ser adicionada em cobertura, seguindo-se as recomendações do Manual de Adubação e de Calagem para os Estados do RS e SC (CQFS RS/SC, 2004). As doses de N, na forma de ureia, foram aplicadas quando as plantas estavam aproximadamente no estádio V3 (Counce et $a l ., 2000)$, um dia antes da entrada da água na área experimental, que ocorreu no dia 04/12/2007. No está- dio R0 (início da diferenciação do primórdio floral) foi realizada a divisão das parcelas em quatro subparcelas, as quais receberam a aplicação de doses de $\mathrm{N}\left(0,25,50\right.$ e $\left.75 \mathrm{~kg} \mathrm{ha}^{-1}\right)$ em cobertura, na forma de ureia, distribuídas ao acaso dentro das parcelas. As parcelas que continham como tratamento principal a dose recomendada pela CQFS RS/SC (2004) receberam a aplicação de $42 \mathrm{~kg} \mathrm{~N} \mathrm{ha}^{-1}$, em substituição à dose de 50 $\mathrm{kg} \mathrm{N} \mathrm{ha-1}$, para que completasse o equivalente a $110 \mathrm{~kg}$ aplicados durante o ciclo da cultura.

\section{Experimento 2}

A semeadura mecanizada, na safra 2008/2009, foi realizada no dia 18/11/2008, a uma profundidade de aproximadamente $3 \mathrm{~cm}$, com densidade de sementes de $110 \mathrm{~kg} \mathrm{ha}^{-1}$ (corrigido o poder germinativo) do cultivar de arroz irrigado IRGA 424, de ciclo médio, de aproximadamente 132 dias. O controle de plantas invasoras foi efetuado com uma aplicação de Bispiribaque sódico, na dose de $65 \mathrm{~mL} \mathrm{ha}{ }^{-1}+4 \mathrm{~g}$ de Metsulfurommetílico, em pós-emergência, no dia 16/12/2008 (23 dias após a emergência das plântulas). Os tratamentos na parcela principal consistiram em seis doses de $\mathrm{N}$ $\left(0,40,58,80,120\right.$ e $\left.160 \mathrm{~kg} \mathrm{ha}^{-1}\right)$, sendo a dose de 58 $\mathrm{kg} \mathrm{N} \mathrm{ha}^{-1}$ correspondente a $60 \%$ da dose de $\mathrm{N}$ a ser adicionada, seguindo-se as recomendações do Manual de Adubação e de Calagem para os Estados do RS e SC (CQFS RS/SC, 2004). Nesta safra, foi incluída uma dose adicional de N (160 kg ha $\left.{ }^{-1}\right)$, para avaliar se haveria resposta, em termos de produtividade de grãos, a doses mais altas que a maior recomendada pelo Manual de Adubação e de Calagem para os Estados do RS e SC (120 kg ha-1) (CQFS RS/SC, 2004), já que, na safra de 2007/2008, foram observadas respostas lineares para produção de matérias verde e seca. As doses de N, na forma de ureia, foram aplicadas quando as plantas estavam aproximadamente no estádio V4 (Counce et al., 2000), um dia antes da entrada da água na área experimental, que ocorreu no dia 17/12/2008. No estádio R0 foi realizada a divisão das parcelas em quatro subparcelas, as quais receberam a aplicação de doses de $\mathrm{N}\left(0,25,50\right.$ e $\left.75 \mathrm{~kg} \mathrm{ha}^{-1}\right)$, na forma de ureia, distribuídas ao acaso dentro das parcelas. As parcelas que continham, como tratamento principal, a dose recomendada pela CQFS RS/SC (2004) receberam a aplicação de $40 \mathrm{~kg} \mathrm{~N} \mathrm{ha}^{-1}$, em substituição à dose de $50 \mathrm{~kg} \mathrm{~N} \mathrm{ha}^{-1}$, para que se completasse o equivalente a $110 \mathrm{~kg}$ aplicados durante o ciclo da cultura.

Os experimentos foram conduzidos com cultivares diferentes, de mesmo ciclo de desenvolvimento, tendo em vista as recomendações para uso do sistema Clearfield. Em ambos os experimentos, após a primeira aplicação de $\mathrm{N}$ em cobertura, foram realizadas as 
leituras com o clorofilômetro, seguindo a escala de Counce et al. (2000). As leituras foram realizadas na última folha completamente expandida, aproximadamente na metade da folha, com 15 leituras na parcela principal e, ou, 15 quando havia parcela subdividida, sendo que todas as leituras foram realizadas sempre no final da tarde, para seguir um mesmo padrão de horário e evitar que as avaliações fossem realizadas no período da manhã, em função do orvalho. Quando as plantas encontravam-se no estádio R0 (Counce et al., 2000) foram coletados dois metros lineares de plantas, para determinação das massas de matérias verde e seca. Posteriormente, determinou-se o teor de $\mathrm{N}$ do tecido vegetal, conforme metodologia descrita por Tedesco et al. (1995). Com base na quantidade de matéria seca produzida e no $\mathrm{N}$ total do tecido das plantas, foi calculado o acúmulo de $\mathrm{N}$ pelas plantas.A produtividade de grãos foi determinada em uma área útil de $8 \mathrm{~m}^{2}$ de cada parcela. As panículas foram trilhadas, a umidade dos grãos foi corrigida para $13 \%$ e a produtividade de grãos expressa em $\mathrm{kg} \mathrm{ha}^{-1}$.

Para produção de matérias verde e seca em função das doses de $\mathrm{N}$, foram ajustadas equações de regressão e, para a produtividade de grãos em função das doses aplicadas, foi realizada análise de variância $(\mathrm{P}<0,05)$ e, quando significativa, ajustadas equações de regressão.

\section{RESULTADOS E DISCUSSÃO}

Na safra 2007/08, as leituras do clorofilômetro, realizadas 19 dias após a primeira aplicação de N evidenciaram o efeito das doses aplicadas, variando de 31,8 até 38,6 unidades SPAD, para os tratamentos sem N, e de $120 \mathrm{~kg} \mathrm{ha}^{-1}$, respectivamente (Figura 1). Considerando-se uma correlação entre leituras e teor de $\mathrm{N}$ das folhas (Pocojeski, 2007; Pit et al., 2007; Jinwen et al., 2009; Lin et al., 2010), o clorofilômetro foi sensível para detectar a resposta da aplicação das doses de $\mathrm{N}$ em cobertura. Entretanto, as leituras do clorofilômetro decresceram rapidamente com o tempo de cultivo, tornando-se semelhantes, em todos os tratamentos (média em torno de 30 unidades SPAD), aos 47 dias após a aplicação, independentemente da dose de $\mathrm{N}$ inicialmente aplicada. Em trabalho desenvolvido por Cancellier et al. (2013), avaliando índices de clorofila em partes da planta de arroz de terras altas, os autores encontraram resultados semelhantes e ressaltam que a retranslocação do nitrogênio acumulado nos tecidos ocorre da parte inferior da planta, ou seja, das folhas fisiologicamente mais velhas para os órgãos mais jovens, justificando-se a homogeneidade das leituras, visto que elas foram realizadas na última folha completamente expandida da planta.
Para a safra 2008/09, as unidades SPAD do clorofilômetro variaram de 27,8 a 37,4, para os tratamentos testemunha ( $\left.0 \mathrm{~kg} \mathrm{~N} \mathrm{ha}^{-1}\right)$, até a quantidade de $160 \mathrm{~kg} \mathrm{~N}$ $\mathrm{ha}^{-1}$, respectivamente, para as leituras realizadas aos 20 dias após a primeira aplicação de N, também evidenciando-se o efeito das doses de $\mathrm{N}$ aplicadas na primeira adubação nitrogenada de cobertura (Figura 2). Entretanto, as leituras do clorofilômetro também decresceram rapidamente com o tempo de cultivo, tornando-se semelhante em todos os tratamentos (entre 28 e 30 unidades SPAD), aos 34 dias após a aplicação (estádio R0, momento da segunda aplicação de N), à semelhança do que ocorreu na safra anterior, exceto para a dose de 160 $\mathrm{kg} \mathrm{N} \mathrm{ha}^{-1}$, em que as leituras ainda ficaram próximas a 33 unidades SPAD. Este fato deve-se, provavelmente, ao efeito de diluição causado pela expansão volumétrica do dossel nas maiores doses aplicadas (Galzerano et al., 2008). As plantas que produzem maiores quantidades de matéria verde apresentam maior efeito de diluição do nutriente e, consequentemente, os valores SPAD tornamse menores. Resultados semelhantes também foram obtidos em trabalho desenvolvido por Guimarães et al. (2011), utilizando Capim Braquiária cv. Marandú, em que os autores observaram que a maior percentagem de matéria seca acumulada em folhas foi relacionada com menores valores SPAD.

Embora as leituras do clorofilômetro estivessem indicando o mesmo estado nutricional das plantas, houve diferença na produção de matérias verde e seca das plantas em R0, que responderam linearmente à primeira aplicação de $\mathrm{N}$ em cobertura (Figura 3). O cultivar de arroz irrigado utilizado na $2^{\mathrm{a}}$ safra também respondeu linearmente à primeira aplicação de $\mathrm{N}$ em cobertura, na produção de matérias verde e seca das plantas de arroz em R0 (Figura 3). Resultados de trabalhos anteriores (Pocojeski, 2007; Pit et al., 2007) já demonstraram que a produção de matérias verde e seca e de $\mathrm{N}$ acumulado respondem linearmente às doses de $\mathrm{N}$ aplicadas. Assim, os resultados de produção de matérias verde e seca ou do $\mathrm{N}$ acumulado poderiam, desde que ajustados de forma adequada, ajudar na interpretação dos resultados das leituras do clorofilômetro, indicando para cada situação de produção de massa de plantas, qual o melhor ajuste da adubação nitrogenada em cobertura.

Esses resultados indicam que a avaliação do estado nutricional das plantas pelo clorofilômetro, isoladamente, não é um bom indicador das condições gerais da cultura e o uso da matéria verde ou da seca pode ajudar na interpretação dos resultados, para um melhor ajuste da adubação em cobertura. Pocojeski (2007) e Pit et al. (2007) têm demonstrado que o uso isolado das leituras do clorofilômetro não é suficiente para predizer a necessidade de adubação nitrogenada e, em função disso, 
tenta-se aliar outros parâmetros da planta que possam complementar, ou ser mais eficientes, na predição da necessidade de N. Porém, não há valores de referência, ou críticos, para os cultivares ou sistemas de produção de arroz irrigado na região sul do Brasil.

Houve efeito da segunda aplicação de N em cobertura, evidenciado pelas leituras do clorofilômetro após 55 dias do alagamento (36 dias após a segunda aplicação) (Figura 1), variando de 27,8 até 35,8 unidades SPAD, dependendo da quantidade de $\mathrm{N}$ aplicado (Figura 1). Entretanto, não houve influência da primeira aplicação de $\mathrm{N}$ sobre os valores de unidades SPAD atingidas com as
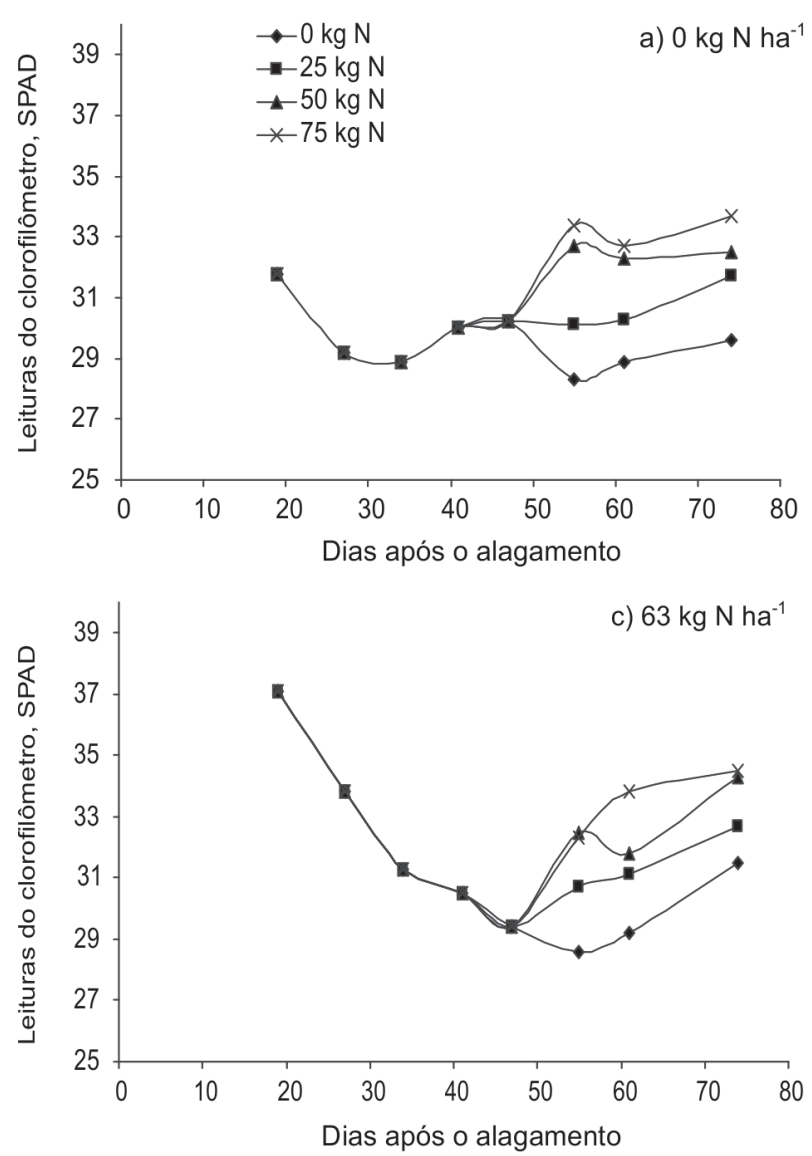

doses da segunda aplicação para os diferentes tratamentos, além do que os valores atingidos foram inferiores aos obtidos com a primeira aplicação. Esse comportamento pode ser explicado pelo fato de que não havia mais diferenças nas leituras SPAD entre os tratamentos quando foi realizada a segunda aplicação. Lima et al. (2012) encontraram resultados semelhantes a este, em experimento avaliando a aplicação de doses de $\mathrm{N}$ na cultura da grama-bermuda, e reafirmam que há diminuição da cor verde das folhas, explicada pela tendência de diminuição da concentração de $\mathrm{N}$ na folha, ao longo do ciclo, resultante do efeito da diluição. Ou seja, nesse estádio,
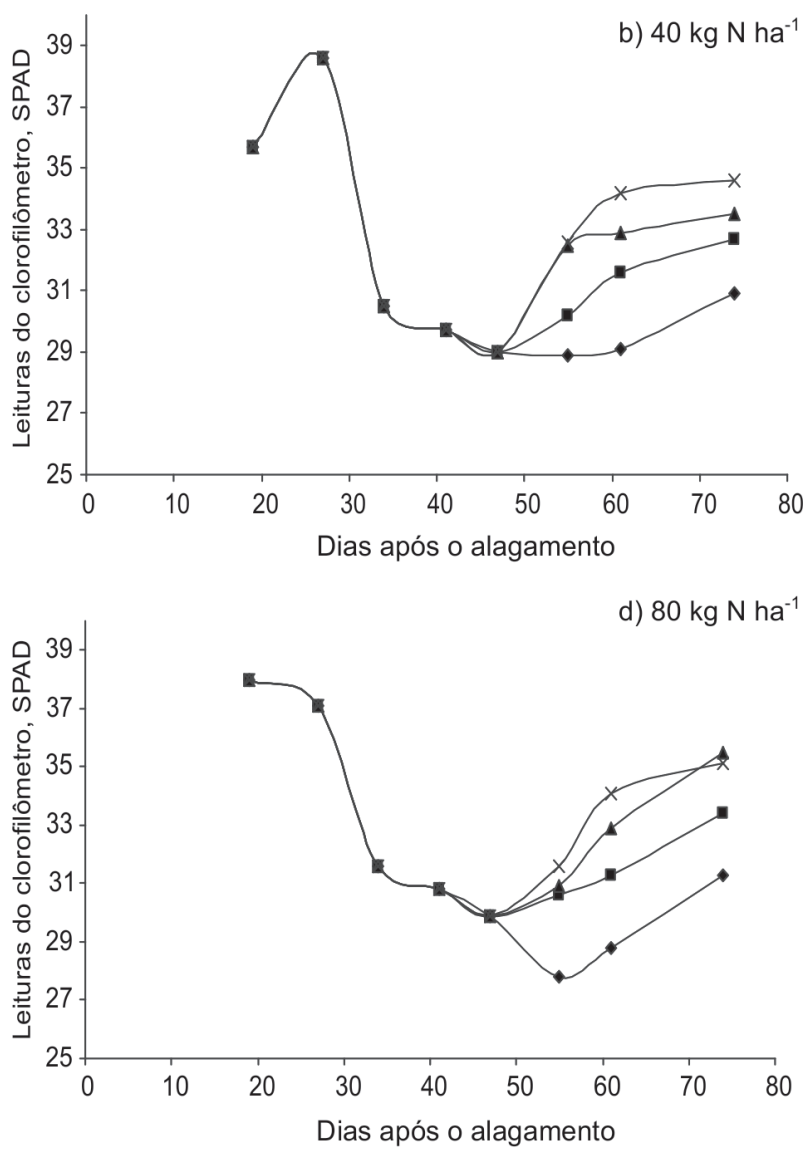

e) $120 \mathrm{~kg} \mathrm{~N} \mathrm{ha}^{-1}$

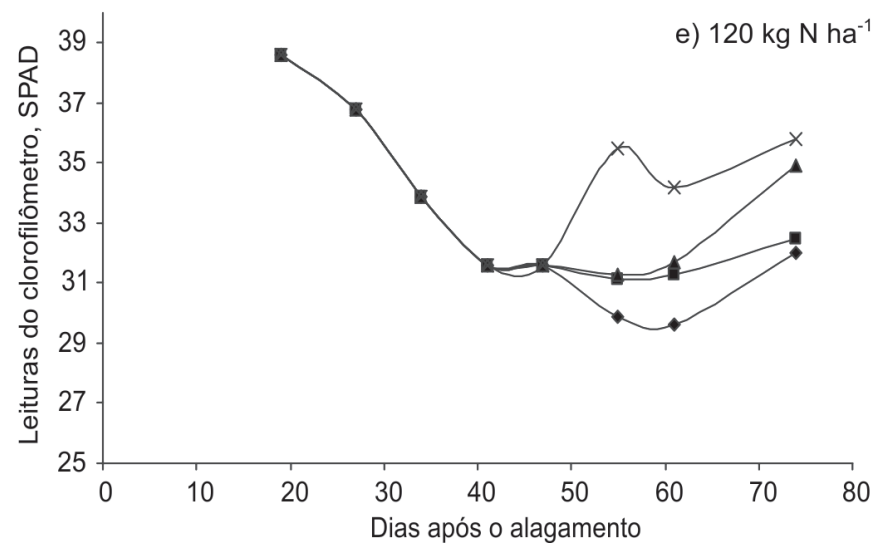

Figura 1. Leituras SPAD, realizadas com clorofilômetro ao longo do ciclo da cultura do arroz irrigado, nos tratamentos com diferentes doses de N na parcela principal (a, b, c, d, e) e nas subparcelas. Cultivar IRGA 422 CL. Safra 2007/2008. Santa Maria - RS.

Rev. Ceres, Viçosa, v. 62, n.3, p. 310-318, mai-jun, 2015 
a quantidade de massa das plantas era muito maior do que na primeira avaliação, diluindo os efeitos do $\mathrm{N}$ aplicado.

Na safra 2008/09, também houve efeito da segunda aplicação de $\mathrm{N}$ em cobertura, nas leituras do clorofilômetro, após 42 dias do alagamento (Figura 2), variando de 29,1 até 36,5 unidades SPAD, dependendo da quantidade de $\mathrm{N}$ aplicada. Entretanto, diferentemente dos resultados obtidos na safra anterior, os valores de leitura SPAD em R0 foram, em alguns tratamentos, superiores aos obtidos na primeira avaliação, indicando que houve influência maior da segunda aplicação de N sobre as leituras do clorofilômetro. Parte deste comportamento diferenciado pode ser atribuída à diferença entre os cultivares utilizados nos dois experimentos. O cultivar IRGA 424, utilizado no segundo experimento, é um cultivar sensível ao efeito residual de herbicida utilizado para controle de arroz vermelho, fato evidenciado pela fitotoxidez observada no experimento, e que pode ter restringido o crescimento das plantas e favorecido o aumento das leituras do clorofilômetro, graças a uma menor produção de matéria seca. Também cabe ressaltar aqui que as leituras do clorofilômetro são afetadas por qualquer alteração da folha, como doenças, fitotoxidez e, segundo Haefele et al. (2010), inclusive pela deficiência nutricional de fósforo, que podem alterar os valores de leitura, quando comparados com os de uma planta considerada sadia ou bem nutrida.
Em experimento desenvolvido com a cultura do feijão irrigado, Barbosa Filho et al. (2009), testando a possibilidade de uso dos resultados do clorofilômetro e de outros parâmetros, comentam que se pode considerar o uso do clorofilômetro Minolta SPAD-502 um método promissor como instrumento indicativo da época de quando se deve iniciar a aplicação de $\mathrm{N}$ em cobertura, no feijoeiro irrigado, e que a adubação de cobertura, baseada nesse critério, resulta em maior eficiência agronômica do $\mathrm{N}$ do que a aplicação de $\mathrm{N}$ baseada na recomendação regional. Porém, a grande limitação do aparelho está em predizer a dose de $\mathrm{N}$ a ser utilizada, muito mais do que a época adequada de aplicação de N. Ou seja, os resultados do experimento também apontam que o aparelho tem a capacidade de diagnosticar as diferenças no teor de $\mathrm{N}$ entre as plantas, porém apresenta limitações, principalmente quando não se considera o efeito de diluição pela produção de matéria verde. Hurtado et al. (2011), em seu trabalho de ajuste de adubação nitrogenada em cobertura para a cultura do milho, utilizando como parâmetro um valor de índice de suficiência de nitrogênio (ISN), durante o ciclo da cultura, mostram resultados indicativos de que o clorofilômetro foi eficiente para predizer o momento de realizar a adubação em cobertura, porém, não a dose de $\mathrm{N}$ a ser utilizada, a partir do valor estimado para o ISN, sugerindo que o uso de um mesmo valor para todo o ciclo da cultura pode não ser a estratégia mais apropriada.

Tabela 1. Produtividade de grãos, em função de doses de nitrogênio em cobertura. Cultivar IRGA 422 CL (safra 2007/2008) e cultivar IRGA 424 (safra 2008/2009). Santa Maria - RS

\begin{tabular}{|c|c|c|c|c|c|c|}
\hline \multirow[t]{3}{*}{$\begin{array}{l}\text { Doses N } \\
\left(\mathrm{kg} \mathrm{ha}^{-1}\right) \text { em Ro }\end{array}$} & \multicolumn{6}{|c|}{$\begin{array}{c}\text { Doses de N }\left(\mathrm{kg} \mathrm{ha}^{-1}\right) \text { - Aplicação em V4 } \\
\text { Safra 2007/2008 }\end{array}$} \\
\hline & $\mathbf{0}$ & 40 & 63 & 80 & 120 & 160 \\
\hline & \multicolumn{6}{|c|}{ kgha $^{-1}$} \\
\hline 0 & 7.049 & 7.004 & 7.556 & 8.246 & 7.943 & - \\
\hline 25 & 6.824 & 8.444 & 8.583 & 7.713 & 7.756 & - \\
\hline $50^{1}$ & 6.458 & 7.486 & 8.671 & 7.909 & 8.350 & - \\
\hline 75 & 7.241 & 7.583 & 8.094 & 8.848 & 7.788 & - \\
\hline $\begin{array}{l}\text { Média* } \\
\end{array}$ & 6.893 & 7.629 & 8.226 & 8.179 & 7.959 & - \\
\hline \multirow[t]{4}{*}{ "Equação } & \multicolumn{6}{|c|}{$\mathrm{y}=6.8518+0.0307 \mathrm{x}-0.0002 \mathrm{x}^{2} ; \mathrm{r}^{2} 0,957$} \\
\hline & \multicolumn{6}{|c|}{ Safra 2008/2009 } \\
\hline & $\mathbf{0}$ & 40 & 58 & 80 & 120 & 160 \\
\hline & \multicolumn{6}{|c|}{$\mathrm{kg} \mathrm{ha}^{-1}$} \\
\hline 0 & 5.932 & 7.327 & 7.447 & 8.116 & 6.228 & 7.721 \\
\hline 25 & 7.106 & 8.208 & 6.871 & 8.052 & 7.882 & 8.236 \\
\hline 50 & 5.811 & 7.079 & 8.220 & 8.313 & 7.986 & 7.175 \\
\hline 75 & 7.015 & 7.382 & 8.217 & 8.267 & 7.413 & 7.421 \\
\hline Média* & 6.466 & 7.499 & 7.689 & 8.187 & 7.377 & 7.638 \\
\hline
\end{tabular}

${ }^{1}$ Para o tratamento 63 e $58 \mathrm{~kg} \mathrm{ha}^{-1} \mathrm{~N}$ foi utilizada a dose de $40 \mathrm{~kg} \mathrm{ha}^{-1} \mathrm{~N}$ em R0. A análise de variância $(\mathrm{P}<0.05)$ indicou efeito principal da aplicação de N somente na parcela principal para a qual foi ajustada equação de regressão. 
Para a safra 2007/08, não houve efeito de interação entre as doses da primeira e da segunda adubação nitrogenada em cobertura, na produtividade de grãos (Tabela 1), e sim, somente efeito principal das doses da primeira aplicação em cobertura, com o ajuste de uma equação quadrática. Neste caso, a primeira adubação nitrogenada em cobertura foi a mais determinante da produtividade, não sendo possível compensar com a segunda aplicação, no caso de baixa disponibilidade de $\mathrm{N}$ na fase inicial (testemunha), ou, mesmo, incrementar
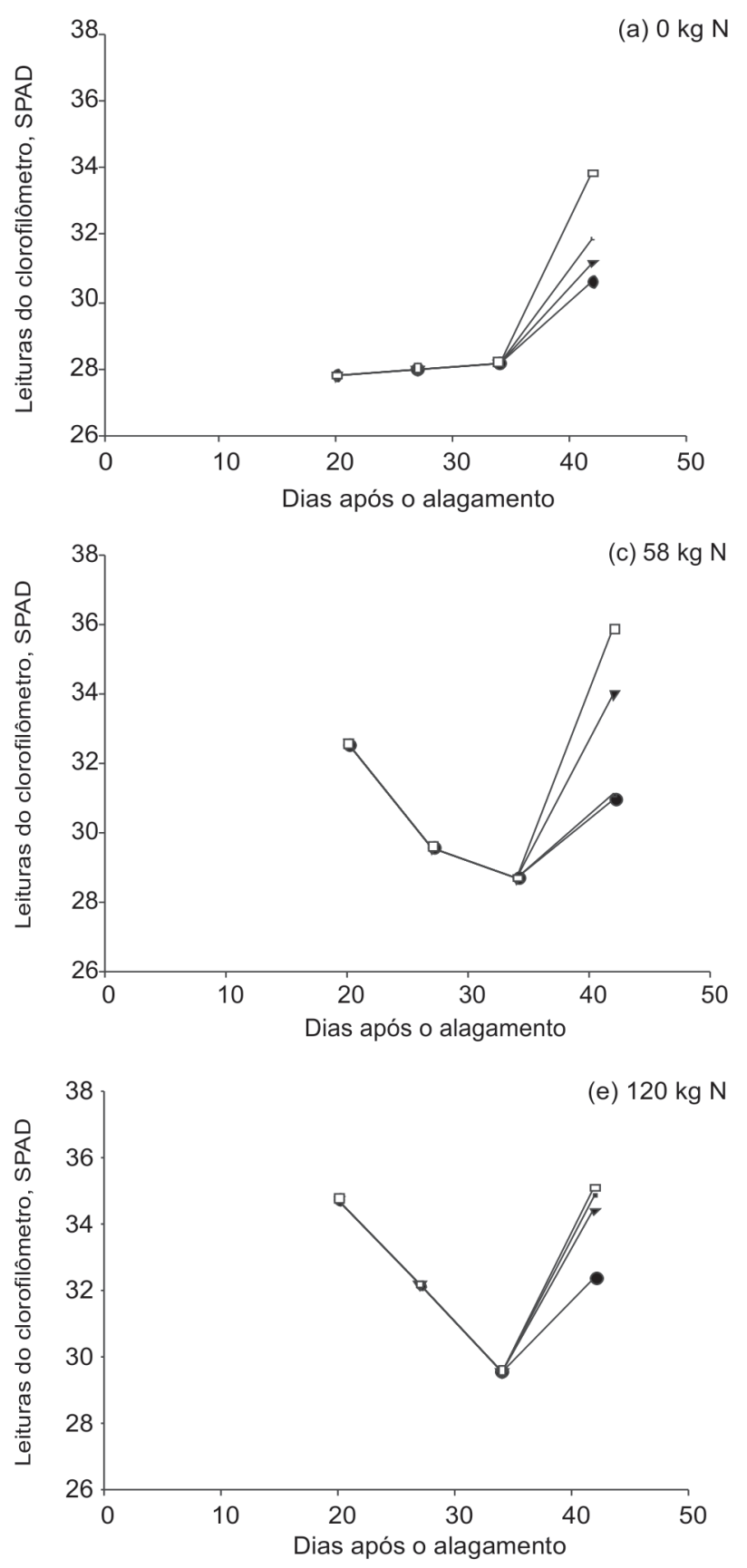

mais a produtividade, nos casos de alta aplicação (80 e $120 \mathrm{~kg} \mathrm{ha}^{-1}$ ). Observa-se que, pelo cruzamento da produtividade de grãos (Tabela 1) e os dados de leituras SPAD (Figura 1) e matéria verde (Figura 3a), as melhores produtividades de grãos foram obtidas quando o arroz havia produzido em torno de $18 \mathrm{Mg} \mathrm{ha}^{-1}$ de matéria verde, em R0, e a leitura SPAD, após a adubação nitrogenada em cobertura, atingido valores de aproximadamente 33 , o que ocorreu quando foram usados entre 40 e $63 \mathrm{~kg} \mathrm{ha}^{-1}$, na primeira aplicação, e completada a dose com o uso

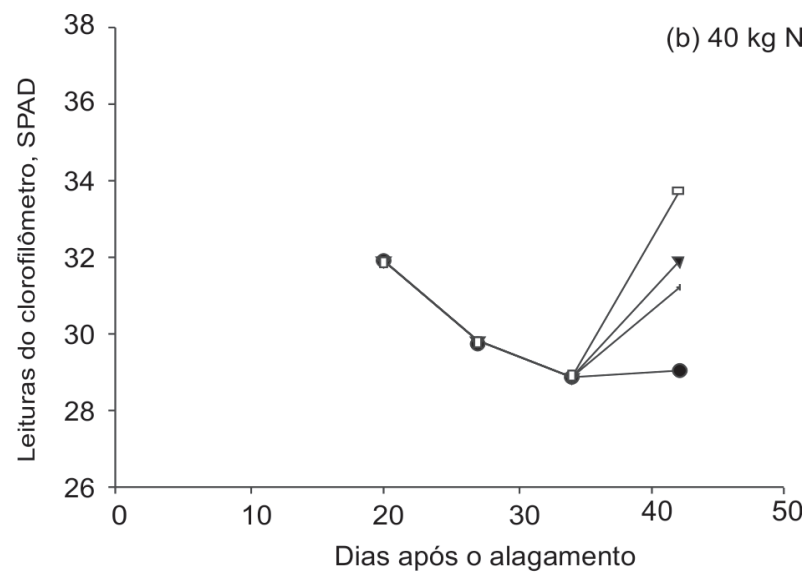

(d) $80 \mathrm{~kg} \mathrm{~N}$
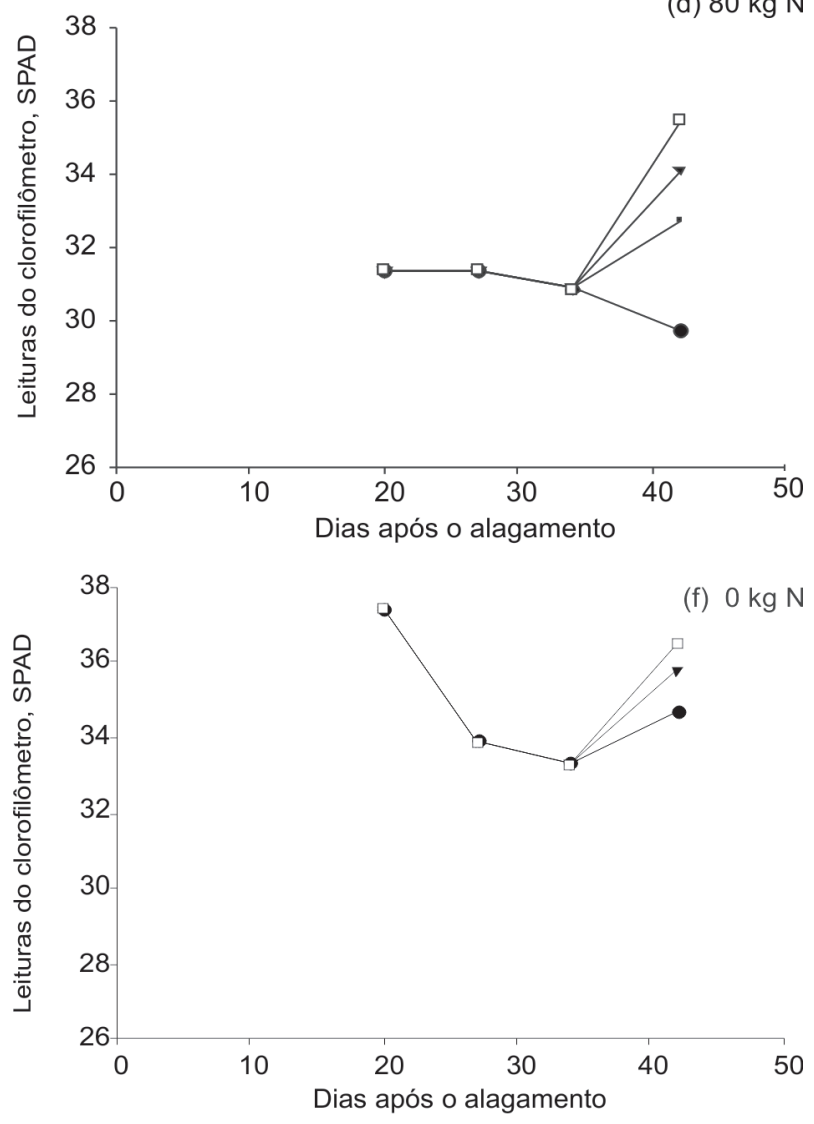

$-0 \mathrm{~N} \rightarrow 25 \mathrm{~N} \rightarrow 50 \mathrm{~N} \quad \square-75 \mathrm{~N}$

Figura 2. Leituras SPAD, realizadas com clorofilômetro ao longo do ciclo da cultura do arroz irrigado, nos tratamentos com diferentes doses de N na parcela principal (a, b, c, d, e, f) e nas subparcelas. Cultivar IRGA 424. Safra 2008/2009. Santa Maria - RS. 
de 25 a $50 \mathrm{~kg} \mathrm{ha}^{-1}$, na segunda aplicação em cobertura, ou seja, está de acordo com as recomendações do Manual de Recomendação de Adubação e Calagem para os estados do RS e SC (CQFS RS/SC, 2004).

Não houve também efeito de interação entre as doses da primeira e da segunda adubação em cobertura com a produtividade de grãos, para a safra 2008/09 (Tabela 1), e, sim, somente efeito principal das doses da primeira aplicação em cobertura, com o ajuste de uma equação quadrática. Pelo cruzamento das produtividades de grãos (Tabela 1) e dos dados de leituras SPAD (Figura 2) e de matéria verde (Figura 3b), as melhores produtividades de grãos foram obtidas quando o arroz havia produzido em torno de $17 \mathrm{Mg} \mathrm{ha}^{-1}$ de matéria verde, em R0, e a leitura SPAD, após a adubação nitrogenada em cobertura, atingido valores entre 31 e 32 , o que ocorreu quando foram usados entre 58 e $80 \mathrm{~kg} \mathrm{ha}^{-1}$, na primeira aplicação, e completada a dose com o uso de 25 a $50 \mathrm{~kg} \mathrm{ha}^{-1}$, na segunda aplicação em cobertura, também concordando com as recomendações do Manual de Recomendação de Adubação e Calagem para os estados do RS e SC (CQFS RS/SC, 2004).
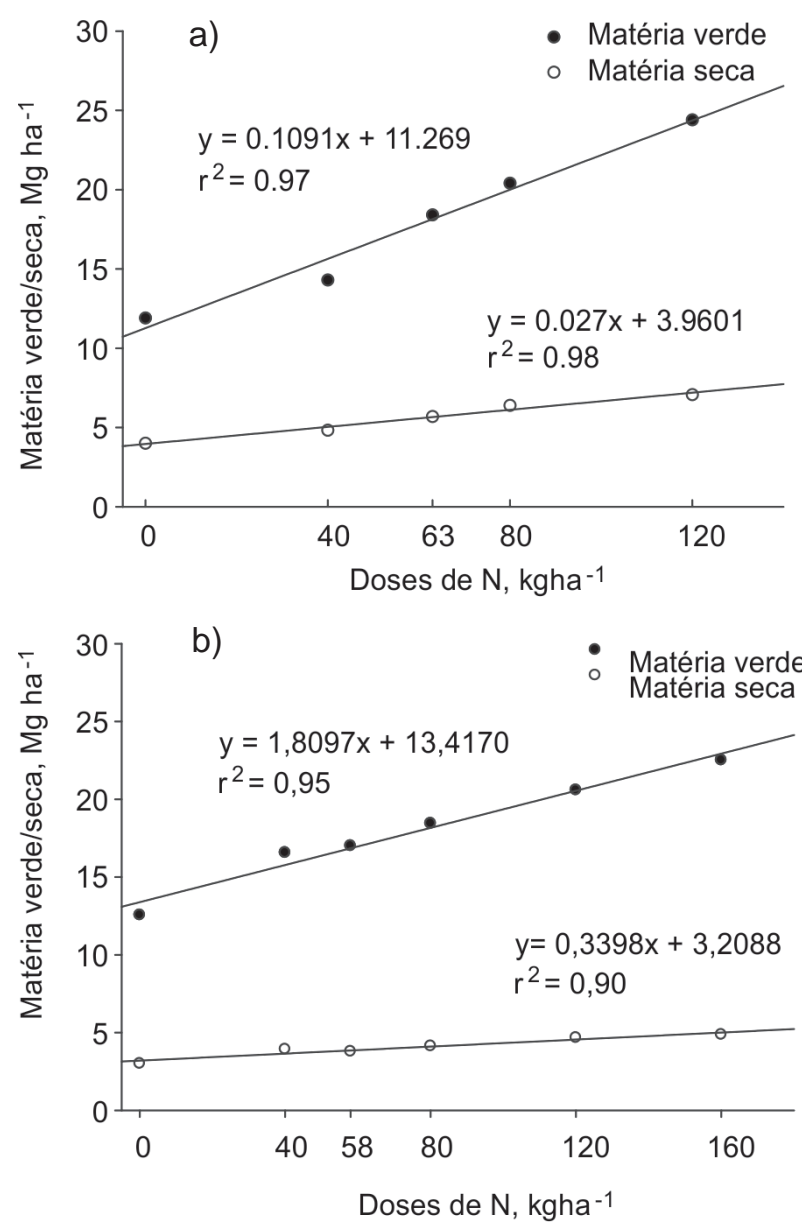

Figura 3. Produção de matérias verde e seca, em R0;(a) cultivar IRGA 422 CL, safra 2007/2008; (b) cultivar IRGA 424, safra 2008/2009. Santa Maria - RS.
Considerando-se as respostas, em termos de leituras do clorofilômetro e a produção de matérias verde e seca das plantas de arroz, poder-se-ia indicar que a cultura apresenta grande potencial de resposta à aplicação de altas doses de N. Porém, quando analisados os dados de produtividade de grãos da cultura, esse potencial não é expresso (Tabela 1), ou seja, embora a planta acumule linearmente o $\mathrm{N}$ aplicado (Figura 4), a produtividade de grãos apresenta resposta quadrática, com o máximo do potencial produtivo expresso em doses inferiores à maior utilizada em cada um dos experimentos, não se justificando a utilização de altas doses de $\mathrm{N}$ para aumentar a produtividade de grãos. Em trabalho desenvolvido por Bredemeier (1999), a massa de matéria seca também foi um dos parâmetros mais precisos para ajustar as leituras do clorofilômetro. Assim, as leituras do clorofilômetro e uma eventual definição de teor crítico de leitura SPAD para o manejo da adubação nitrogenada para a cultura do arroz irrigado devem ser usadas com cautela, pois isoladamente não indicam o estado nutricional da cultura e a produção de matérias verde e seca (ou o N acumulado na lavoura) deve ser considerada.
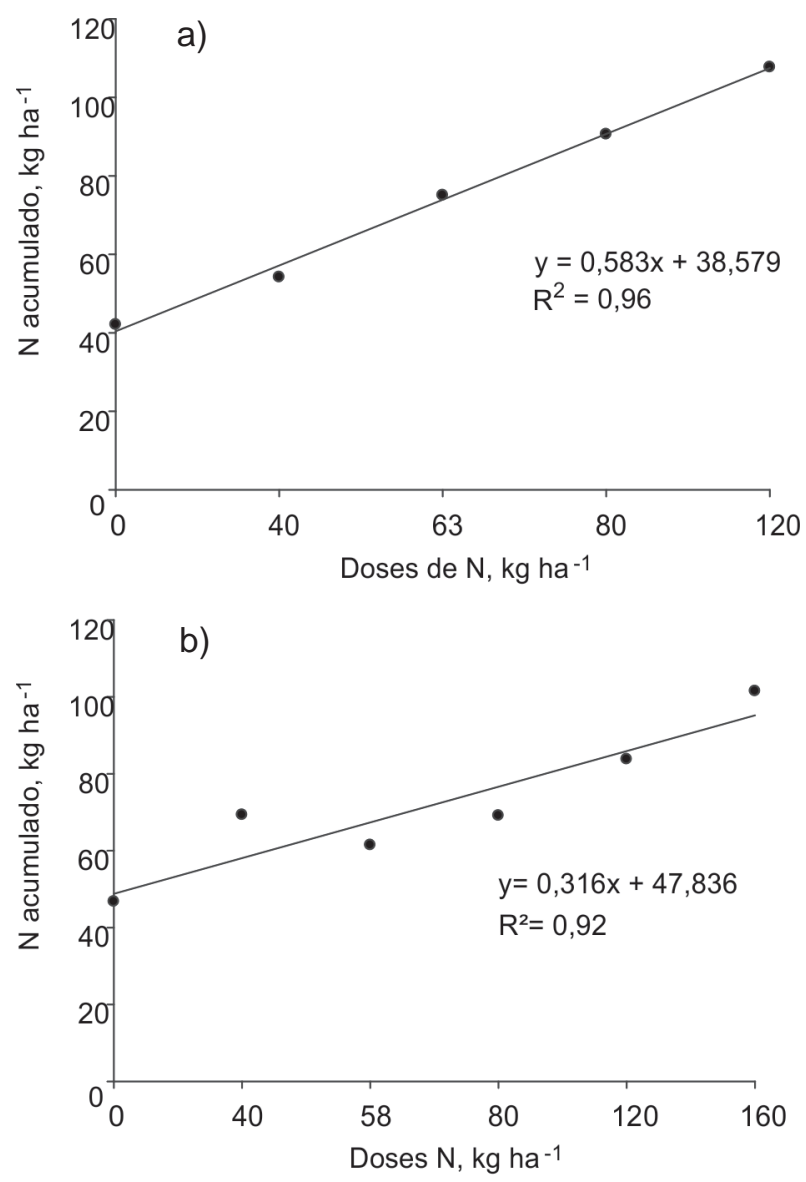

Figura 4. Teor de $\mathrm{N}$ acumulado na matéria seca das plantas de arroz irrigado em função das doses de N. (a) Cultivar IRGA 422 CL, Safra 2007/2008; (b) Cultivar IRGA 424. Safra 2008/2009. Santa Maria - RS. 
Considerando-se que foram utilizados dois cultivares de arroz irrigado, para realizar-se uma comparação entre eles, não foram encontradas diferenças contrastantes na obtenção dos resultados, provavelmente por ambos apresentarem o mesmo ciclo de desenvolvimento e, possivelmente, coloração da folha muito semelhante. Cabe ressaltar, como já comentado anteriormente, que não foi possível conduzir os dois cultivares sob as mesmas condições, já que o cultivar IRGA 424 sofreu estresse por fitotoxicidade. Ou seja, a diferença encontrada entre os dois pode estar atrelada também a este fato. Sugere-se que outros experimentos sejam realizados com cultivares de ciclos diferentes.

\section{CONCLUSÕES}

A avaliação do estado nutricional das plantas apenas com o clorofilômetro não se mostrou um bom indicador para predizer a necessidade de aplicação complementar de N.

Os parâmetros matérias verde e seca demonstraram potencial para serem utilizados em conjunto com as leituras do clorofilômetro, mas há que se determinar os valores críticos em que a planta expressa seu máximo potencial produtivo com retorno econômico.

Para este estudo, os valores de leitura do clorofilômetro que representaram as maiores produtividades de grãos foram obtidos entre 31 e 33 unidades SPAD, em R0, associados a uma produção de matéria verde de 17 a $18 \mathrm{Mg} \mathrm{ha}^{-1}$, para os cultivares IRGA 422CL e IRGA 424.

\section{AGRADECIMENTOS}

Os autores agradecem ao CNPq, pela concessão das bolsas de Produtividade em Pesquisa e de Iniciação Científica e pelo auxílio financeiro ao projeto. À CAPES, pela concessão de bolsa de estudos.

\section{REFERÊNCIAS}

Argenta G, Silva PRF da \& Bortolin CG (2001) Clorofila na folha como indicador do nível de nitrogênio em cereais. Ciência Rural, 31:715-722.

Argenta G, Silva PRF, Mielnickuz J \& Bortolini CG (2002) Parâmetros de planta como indicadores do nível de nitrogênio na cultura do milho. Pesquisa Agropecuária Brasileira, 37:519-527.

Barbosa Filho MP, Cobucci T, Fageria NK \& Mendes PN (2009) Época de aplicação de nitrogênio no feijoeiro irrigado monitorada com auxílio de sensor portátil. Ciência Agrotécnica, 33:425-431.

Bredemeier C (1999) Predição da necessidade de nitrogênio em cobertura em trigo e aveia. Dissertação de Mestrado. Universidade Federal do Rio Grande do Sul, Porto Alegre. 101p.

Cancellier EL, Silva J, Santos MM dos, Siebeneichler SC \& Fidelis RR (2013) Índices de clorofila em partes da planta de arroz de terras altas. Revista Verde de Agroecologia e Desenvolvimento Sustentável, 8:199-206.

Comissão De Química E Fertilidade Do Solo - RS/SC (2004) Manual de adubação e calagem para os Estados do Rio Grande do Sul e Santa Catarina. Porto Alegre, SBCS-NRS/EMBRAPA-CNPT. 400p.
Counce PA, Keisling TC \& Mitchell AJ (2000) A uniform, objective, and adaptive system for expressing rice development. Crop Science, 40:436-443.

Embrapa (2013) Centro Nacional de Pesquisa de Solos. Sistema Brasileiro de Classificação de Solos. $3^{a}$ ed. Rio de Janeiro, Embrapa Solos. 353p.

Fontes PCR (2001) Diagnóstico do estado nutricional das plantas. $1^{\mathrm{a}}$ ed. Viçosa, UFV. 122p.

Galzerano L, Rossiello ROP, Oliveira APP, Paciullo DSC, Morenz MJF \& Silva RP (2008) Mudanças em atributos estruturais de dosséis do capim-Tifton 85 , na fase de estabelecimento, induzidas pela adubação nitrogenada. Boletim de Indústria Animal, 65:329-336.

Guimarães MMC, Matsumoto SN, Figueiredo MP, Cruz PG \& Araújo GS (2011) Estimativa da composição química do Capim Braquiária cv. Marandú por meio de um clorofilômetro portátil. Pesquisa Aplicada \& Agrotecnologia, 4:85-91.

Haefele SM, Siopongco JDLC, Amarante STA \& Tuong TP(2010) Effect of abiotic stresses on the nondestructive estimation of rice leaf nitrogen concentration. International Journal of Agronomy, 2010:1-11.

Hurtado SMC, Resende AV, Silva CA, Corazza EJ \& Shiratsuchi LS (2011) Clorofilômetro no ajuste da adubação nitrogenada em cobertura par ao milho de alta produtividade. Ciência Rural, 41:1011-1017.

Jinwen L, Jingping Y, Pinpin F, Junlan S, Dongsheng L, Changshui G \& Wenyue C (2009) Responses of rice leaf thickness, SPAD readings and chlorophyll a/b ratios to different nitrogen suplly rates in paddy field. Field Crops Research, 114:426-432.

Lima CP de, Backes C, Fernandes DM, Santos AJM, Godoy LJG \& Villas Bôas RL (2012) Uso de índices de reflectância das folhas para avaliar o nível de nitrogênio em grama-bermuda. Ciência Rural, 42:1568-1574.

Lin FF, Qiu LF, Deng JS, Shi YY, Chen LS \& Wang K (2010) Investigation of SPAD meter-based indices for estimation rice nitrogen status. Computers and Electronics in Agriculture, 71:60-65.

Moreno JA (1961) Clima do Rio Grande do Sul. Porto Alegre, Secretaria da Agricultura. 41p.

Peng S, García FV, Laza RC \& Cassman LK (1993) Adjustment for specific leaf weight improves chlorophyll meter's estimate of rice leaf nitrogen concentration. Agronomy Journal, 85:987-990.

Peng S, García FV, Laza RC, Sanico AL, Visperas RM \& Cassman KG (1996) Increased N-use efficiency using a chlorophyll meter on highyielding irrigated rice. Field Crops Research, 47:243-252.

Pit LL, Silva LS, Pocojeski E, Graupe FA \& Rossi JB (2007) Adubação nitrogenada na cultura do arroz irrigado por alagamento monitorada pelo clorofilômetro. In: $31^{\circ}$ Congresso Brasileiro de Ciência do Solo. Gramado. Anais, Sociedade Brasileira de Ciência do Solo. CD ROM.

Pocojeski E (2007) Estimativa do estado nutricional de arroz irrigado por alagamento. Dissertação de Mestrado. Universidade Federal de Santa Maria, Santa Maria. 97p.

Pocojeski, E, Silva LS, Kaefer S, Griebeler G, Guterres AP \& Bredow T (2008) Uso do clorofilômetro para o ajuste da adubação nitrogenada na cultura do arroz irrigado. In: $28^{\text {a }}$ Reunião Brasileira de Fertilidade do Solo e Nutrição de Plantas, $7^{a}$ Reunião Brasileira sobre Micorrizas, $10^{\circ}$ Simpósio Brasileiro de Microbiologia do Solo, $7^{\mathrm{a}}$ Reunião Brasileira de Biologia do Solo. Londrina. Anais, Sociedade Brasileira de Ciência do Solo. CD ROM.

Ricecheck (2006) Recommendations: A guide for rice crop management for improving yields, grain quality and profits and environmental sustainability. NSW Departament of Primary Industries. 23p.

Turner FT \& Jund MF (1991) Chlorophyll meter to predict nitrogen top dress requirement for semi dwarf rice. Agronomy Journal, 83:926-92.

Tedesco JM, Gianello C, Bissani CA, Bohnen H \& Volkweiss SJ (1995) Análise de solos, plantas e outros materiais. Porto Alegre, Universidade Federal do Rio Grande do Sul. 174p.

Rev. Ceres, Viçosa, v. 62, n.3, p. 310-318, mai-jun, 2015 